\title{
ENETS Consensus Guidelines Update for Gastroduodenal Neuroendocrine Neoplasms
}

\author{
G. Delle Fave ${ }^{a} \quad$ D. O'Toole ${ }^{b} \quad$ A. Sundin ${ }^{c} \quad$ B. Taald P. Ferolla e J.K. Ramage ${ }^{f}$ \\ D. Ferone ${ }^{g} \quad$ T. Ito $^{\text {h }} \quad$ W. Weber ${ }^{i} \quad$ Z. Zheng-Pei ${ }^{j} \quad$ W.W. De Herder ${ }^{k} \quad$ A. Pascher ${ }^{\prime}$ \\ P. Ruszniewskim all other Vienna Consensus Conference participants
}

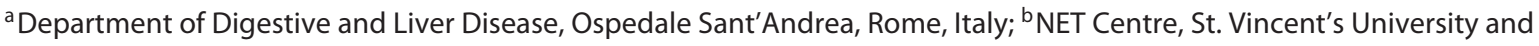
Department of Clinical Medicine, St. James Hospital and Trinity College, Dublin, Ireland; ' Department of Radiology, Section for Molecular Imaging, University Hospital, Uppsala, Sweden; ${ }^{\mathrm{d}}$ Netherlands Cancer Centre, Lijnden, The Netherlands; eNET Centre, Umbria Regional Cancer Network, Università degli Studi di Perugia, Perugia, Italy; ${ }^{\mathrm{f} G a s t r o e n t e r o l o g y ~ D e p a r t m e n t, ~}$ Hampshire Hospitals NHS Trust, Hampshire, UK; ${ }^{9}$ Department of Endocrine and Metabolic Sciences, University of Genoa, Genoa, Italy; ${ }^{h}$ Pancreatic Diseases Branch, Kyushu University Hospital, Fukuoka, Japan; 'Department of Radiology, Memorial Sloan Kettering Cancer Center, New York, N.Y., USA; jDepartment of Endocrinology, Peking Union Medical College Hospital, Beijing, China; ${ }^{k}$ Department of Internal Medicine, Division of Endocrinology, Erasmus Medical Center, Rotterdam, The Netherlands; 'Department of Visceral and Transplant Surgery, Campus Virchow Klinikum, Charité Universitätsmedizin Berlin, Berlin, Germany; ${ }^{\mathrm{m}}$ Department of Gastroenterology, Beaujon Hospital, Clichy, France
\end{abstract}

\section{Introduction}

Gastric neuroendocrine neoplasms (g-NENs) represent the most frequent digestive NENs and are increasingly recognized due to expanding indications of upper gastrointestinal endoscopy. Often silent and benign, gNENs may however be aggressive when sporadic and may sometimes mimic the course of gastric adenocarcinoma. Duodenal neuroendocrine neoplasms (d-NENs) may be sporadic or associated with multiple endocrine neoplasia type 1 (MEN-1) and present with a functional syndrome (i.e. gastrinoma with Zollinger-Ellison syndrome).

Since the last ENETS guidelines [1], new data have become available, especially focusing on g-NENs, while few changes have been reported concerning d-NENs over the last three years.

For an alphabetical list of all other Vienna Consensus Conference participants, see Appendix.

\section{KARGER}

E-Mail karger@karger.com

www.karger.com/nen

\section{Epidemiology}

New epidemiological data come from a study performed in Argentina [2], showing that g-NENs and d-NENs represent 6.9 and $2.0 \%$ of all digestive NENs, respectively. These data are similar to the SEER data, where g-NENs were found to represent $8.7 \%$ of all enteric NENs [3], and quite similar to a recent prospective Austrian study by Niederle et al. [4], where g-NENs represented $5.6 \%$ of all digestive NENs. The proportions of g-NENs with respect to the overall NEN rates do vary, however; g-NENs represented $23 \%$ of all NENs in the Austrian study compared to $6 \%$ in the SEER data, $5 \%$ in a Canadian study (Ontario) and $7.4 \%$ in a Taiwanese study [4-7]. These differences underline the need for multicenter prospective studies with long-term analysis to better describe the European epidemiology of these tumors. 
Table 1. Classification of g-NENs

\begin{tabular}{llll}
\hline & Type 1 & Type 2 & Type 3 \\
\hline Proportion among g-NENs, $\%$ & $70-80$ & $5-6$ & $14-25$ \\
\hline Tumor characteristics & $\begin{array}{l}\text { Often small }(<1-2 \mathrm{~cm}), \text { multiple in } \\
65 \% \text { of cases, polypoid in } 78 \% \text { of cases }\end{array}$ & $\begin{array}{l}\text { Often small }(<1-2 \mathrm{~cm}) \\
\text { and multiple, polypoid }\end{array}$ & $\begin{array}{l}\text { Unique, often large }(>2 \mathrm{~cm}) \\
\text { polypoid and ulcerated }\end{array}$ \\
\hline Associated conditions & Atrophic body gastritis & Gastrinoma/MEN-1 & None \\
\hline Pathology & G1-G2 NET & G1-G2 NET & G3 NEC \\
\hline Serum gastrin levels & $\uparrow$ & $\uparrow$ & Normal \\
\hline Gastric pH & $\uparrow \uparrow$ & $\downarrow \downarrow$ & Normal \\
\hline Metastases, $\%$ & $2-5$ & $10-30$ & $50-100$ \\
\hline Tumor-related deaths, $\%$ & 0 & $<10$ & $25-30$ \\
\hline
\end{tabular}

\section{Clinical and Histological Features}

Well-differentiated g-NENs may be divided into three types (table 1): type 1 and 2 are ECLomas, due to chronic hypergastrinemia, associated with chronic atrophic gastritis (CAG) and Zollinger-Ellison syndrome, respectively. Type 3 g-NENs are rare and sporadic and are not a consequence of an underlying gastric mucosal abnormality; they are mostly single large lesions with a high metastatic potential and with a high grade (often G3 NEC) $[8,9]$. Some issues remain open with respect to the above definitions, as well-differentiated g-NENs with a range of grades (G1-G3) not associated with CAG have been described [10-12], and thus a further distinction among type 3 g-NENs may be appropriate. Mixed gastric neoplasms as endocrine/exocrine have also been described; 68 cases have been reported in the literature so far, but no data about the patients' survival rate are available [13].

\section{Prognosis and Survival}

The overall outcome in type $1 \mathrm{~g}$-NENs is universally excellent; when managed by endoscopic surveillance and lesion resection for larger lesions, recurrence-free survival of approximately 24 months can be achieved with a $100 \%$ survival rate. Data on metastatic rates for types 2 and 3 g-NENs have not significantly changed since the last ENETS guidelines [1, 14]. Similarly, no new data regarding d-NENs survival rates have been reported.

\section{Diagnosis and Tumor Staging}

Upper gastrointestinal endoscopy with careful appraisal of the tumor(s) and background gastric mucosa is still the gold standard in diagnosing g- and d-NENs. Endoscopic ultrasonography also plays a pivotal role in locoregional evaluation, but the cut-off in terms of size when defining the indication for this examination in type 1 NENs needs to be investigated. Conventional imaging techniques such as CT scan and MRI are of very limited value for small type 1 and 2 tumors of the stomach and duodenum in terms of cost/benefit ratio, while they are needed for disease staging in advanced neoplasms and in type 3 NENs. Data concerning the application of somatostatin receptor imaging (either using somatostatin receptor scintigraphy or ${ }^{68} \mathrm{Ga}$-PET-DOTANOC) in these patients are scanty. These examinations are rarely useful for type $1 \mathrm{~g}$-NENs that are invariably small and indolent, but they can be useful in type 2 and 3 g-NENs as part of the overall staging and perhaps choosing therapy [1517]. Larger cohort studies with long-term follow-up are needed to evaluate the clinical usefulness of these tests both in $\mathrm{g}$ - and in d-NENs.

\section{Treatment}

In patients with type 1 g-NENs (fig. 1), conservative management strategies are to be preferred over surgery. Previously, the ENETS guidelines recommended surveillance after 1-2 years and resection for lesions $\geq 1 \mathrm{~cm}$ or those threatening the deep muscularis propria to avoid 
metastatic spread. Some investigators have advocated resecting all visible lesions using biopsy forceps for small lesions and endoscopic mucosal resection (EMR) for lesions $>5 \mathrm{~mm}[18,19]$; however, there are no randomized data comparing an aggressive endoscopic approach (resecting all visible tumors) to more selective endoscopic therapy (resecting only larger lesions). The overall metastatic risk is low in type $1 \mathrm{~g}$-NENs and has been directly correlated with tumor size $(10 \mathrm{~mm}$ appearing to be the cut-off) [20]. Therefore, the minimal approach should be to resect tumors $\geq 10 \mathrm{~mm}$. Resection should be performed by experienced endoscopists in gastric tumors using either EMR or endoscopic submucosal dissection (ESD); the latter has the benefit of an en bloc resection for complete histological appraisal and has been shown effective in a total of 96 patients [21-24]. Nonetheless, EMR and ESD do carry risks of bleeding and perforation. A randomized trial comparing a less aggressive therapy to more aggressive endoscopic therapies is needed. It is also important to carefully analyze the non-involved adjacent gastric mucosa for dysplasia in a background of CAG, and mapping biopsies are recommended. For patients with type 1 tumors that are predicted T2 or with positive margins, local excision or partial gastrectomy should be discussed; surgical antrectomy to suppress hypergastrinemia and limit ECL growth is still debated [1] but rarely practiced as completeness of antrectomy remains speculative.

Somatostatin analogues (SSAs) have been used in limited series in patients with type $1 \mathrm{~g}-\mathrm{NENs}$; they do lead to regression of tumors but this has not been compared to surveillance strategies and as such cannot be recommended in early disease. SSAs might be useful to treat patients with multiple small lesions that are hard to eradicate endoscopically [25], but RCTs comparing their efficacy to endoscopic management are needed to confirm this hypothesis. Their use can be an option for patients with metastatic disease, proven SSTR2 expression and a low Ki-67 index. The gastrin receptor antagonist netazepide has been shown to have anti-proliferative properties in g-NENs in non-controlled studies $[26,27]$. Again, its use cannot be universally recommended and needs to be tested in RCTs.

For type $2 \mathrm{~g}$-NENs, treatment is usually dictated by the possible presence of duodenal or pancreatic NENs as part of MEN-1, and local or limited excision can be recommended, but this should be patient tailored at multidisciplinary NET centers of excellence. Netazepide is also being tested in a trial enrolling patients with type 2 neoplasms [NCT01322542].

ENETS Consensus Guidelines Update for g-NENs

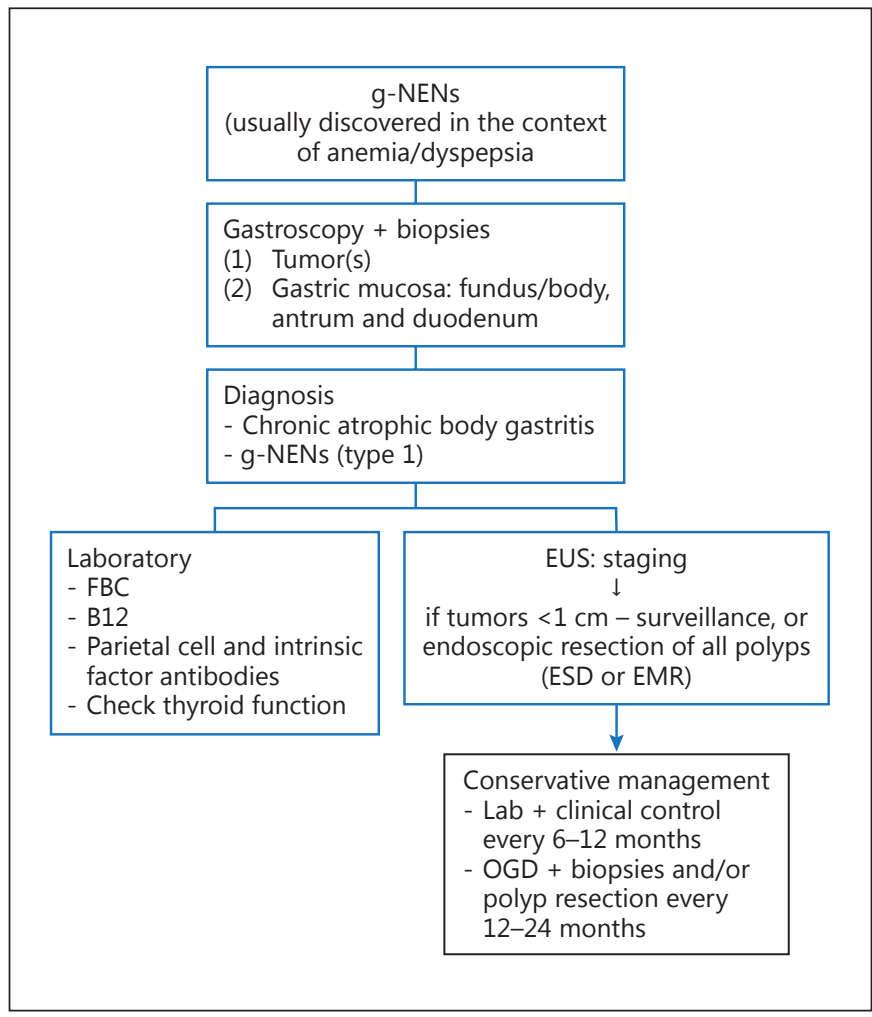

Fig. 1. Algorithm for type 1 g-NEN management. EUS = Endoscopic ultrasonography; FBC = full blood count; OGD = oesophageal gastroduodenal endoscopy.

In patients with type 3 g-NENs, while endoscopic management for small lesions has been proposed $[1,28]$, surgical treatment remains the recommended option and follows the strategy employed for gastric adenocarcinomas (partial or total gastrectomy with lymph node dissection). Systemic therapies are required for inoperable or stage 4 disease.

For d-NENs, endoscopic management has been proven to be safe and effective for lesions $\leq 10 \mathrm{~mm}$ in size, confined to the submucosal layer, without lymph node or distant metastasis (fig. 2). In a series of 38 patients diagnosed over a 5-year period, no recurrence was observed at a mean follow-up of 17 months, and ESD achieved a higher rate of radical excision than EMR [24]. Surgery should be performed for suspected T2 tumors or in those with positive margins after resection (local excision and antrectomy or total gastrectomy depending on tumorhistological features and invasion).

Neuroendocrinology 2016;103:119-124 121 


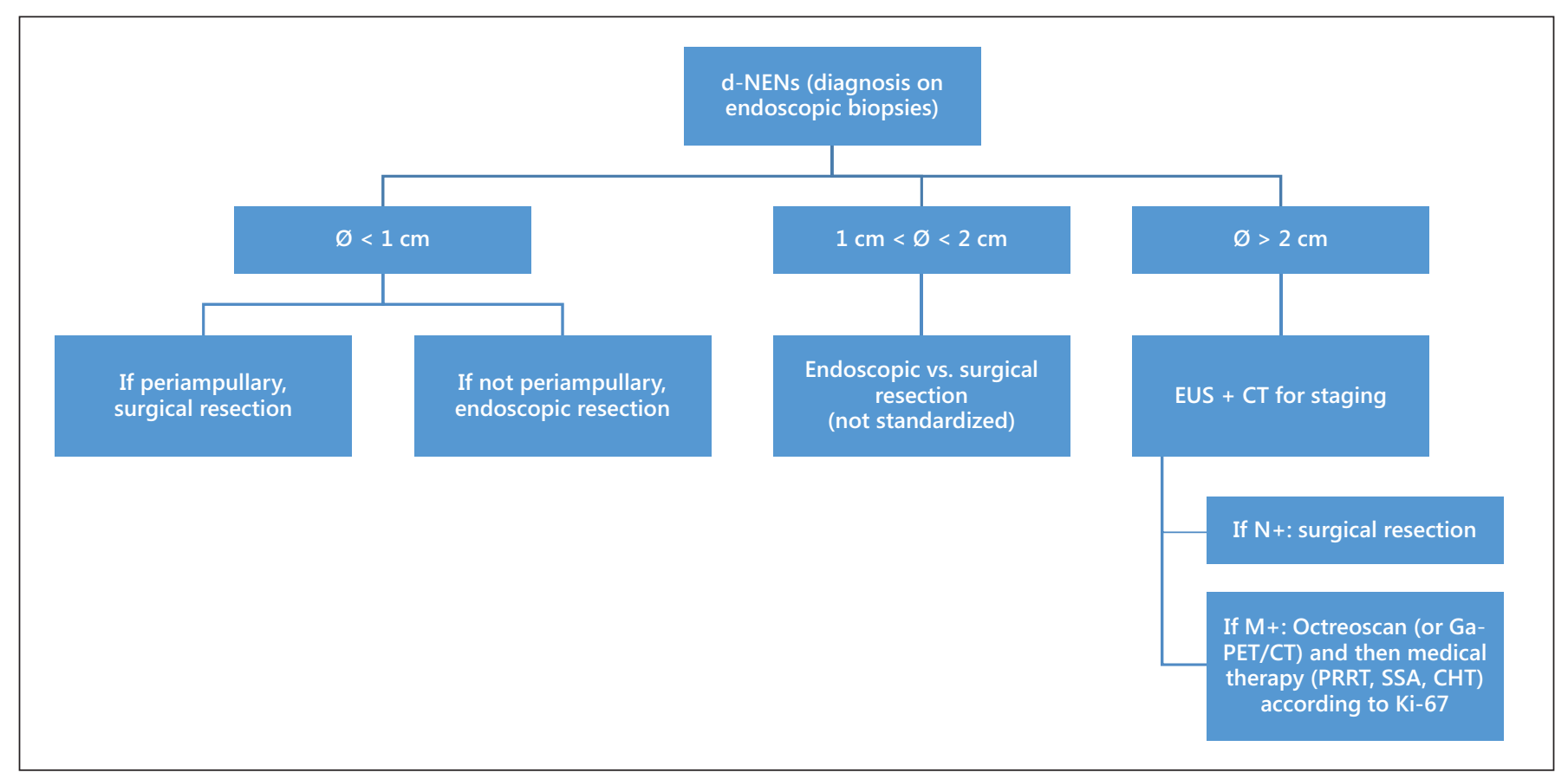

Fig. 2. Algorithm for d-NENs. EUS = Endoscopic ultrasonography; $\mathrm{N}+=$ positive lymph nodes; $\mathrm{M}+=$ positive for metastasis; $\mathrm{CHT}=$ chemotherapy.

\section{Follow-Up}

Endoscopic follow-up is recommended for patients with g- and d-NENs following excision, but the correct timing has never been defined. It is recommended that patients undergo endoscopy at least every 2 years. For type $1 \mathrm{~g}$-NENs, an approach based on tumor recurrence has been proposed, but it has never been validated in prospective trials. Patients with CAG also require careful surveillance for apparition of intestinal metaplasia and dysplasia using modern endoscopic equipment $[29,30]$.

Please also refer to the ENETS consensus guideline updates for other gastroenteropancreatic neuroendocrine tumors [31-36, this issue].

\section{Appendix}

All Other Vienna Consensus Conference Participants

Anlauf, M. (Institut für Pathologie und Zytologie, St. Vincenz Krankenhaus, Limburg, Germany); Bartsch, D.K. (Department of Surgery, Philipps University, Marburg, Germany); Baudin, E. (Institut Gustave Roussy, Villejuif, France); Capdevila, J. (Institute of Oncology, Vall d'Hebron University Hospital, Barcelona, Spain); Caplin, M. (Neuroendocrine Tumour Unit, Royal Free Hospital,
London, UK); Costa, F. (Centro de Oncologia, Hospital Sírio Libanês, São Paulo, Brazil); Cwikla, J.B. (Department of Radiology, Faculty of Medical Sciences, University of Warmia and Mazury, Olsztyn, Poland); Eriksson, B. (Department of Endocrine Oncology, University Hospital, Uppsala, Sweden); Falconi, M. (Department of Surgery, San Raffaele Hospital, Università Vita e Salute, Milan, Italy); Garcia-Carbonero, R. (Medical Oncology Department, Hospital Universitario Doce de Octubre, Madrid, Spain); Gross, D. (Department of Endocrinology and Metabolism, Hadassah University Hospital, Mevasseret Tsion, Israel); Jensen, R.T. (Digestive Diseases Branch, NIH, Bethesda, Md., USA); Kaltsas, G. (Department of Pathophysiology, Division of Endocrinology, National University of Athens, Athens, Greece); Kelestimur, F. (Department of Endocrinology, Erciyes University Medical School, Kayseri, Turkey); Kianmanesh, R. (Department of Surgery, CHU Robert Debré, Reims, France); Klöppel, G. (Institute of Pathology, Technische Universität München, Munich, Germany); Knigge, U. (Neuroendocrine Tumor Center of Excellence, Rigshospitalet, Copenhagen University Hospital, Copenhagen, Denmark); KosKudla, B. (Department of Endocrinology, Medical University of Silesia, Katowice, Poland); Krenning, E. (Department of Internal Medicine, Division of Nuclear Medicine, Erasmus Medical Center, Rotterdam, The Netherlands); Kwekkeboom, D. (Department of Internal Medicine, Division of Nuclear Medicine, Erasmus Medical Center, Rotterdam, The Netherlands); Niederle, B. (Department of Surgery, Medical University of Vienna, Vienna, Austria); Öberg, K. (Department of Medical Sciences, Endocrine Oncology Unit, University Hospital, Uppsala, Sweden); O'Connor, J. (Department of Clinical Oncology, Institute Alexander Fleming, 
Buenos Aires, Argentina); Pape, U.-F. (Department of Hepatology and Gastroenterology, Campus Virchow Klinikum, Charité Universitätsmedizin Berlin, Berlin, Germany); Pavel, M. (Department of Hepatology and Gastroenterology, Campus Virchow Klinikum, Charité Universitätsmedizin Berlin, Berlin, Germany); Perren, A. (Institute of Pathology, University of Bern, Bern, Switzerland); Raymond, E. (Oncologie Médicale, Hôpitaux Universitaires Paris Nord Val de Seine, Paris, France); Reed, N. (Beatson Oncology Centre, Gartnavel General Hospital, Glasgow, UK); Rindi, G. (In- stitute of Anatomic Pathology, Policlinico A. Gemelli, Università Cattolica del Sacro Cuore, Rome, Italy); Sedlackova, E. (Department of Oncology, First Faculty of Medicine and General Teaching Hospital, Prague, Czech Republic); Sorbye, H. (Department of Oncology, Haukeland University Hospital, Bergen, Norway); Toumpanakis, C. (Neuroendocrine Tumour Unit, Royal Free Hospital, London, UK); Wiedenmann, B. (Department of Hepatology and Gastroenterology, Campus Virchow Klinikum, Charité Universitätsmedizin Berlin, Berlin, Germany).

\section{References}

1 Delle Fave G, Kwekkeboom DJ, Van Cutsem E, et al: ENETS consensus guidelines for the management of patients with gastroduodenal neoplasms. Neuroendocrinology 2012;95:7487.

2 O'Connor JM, Marmissolle F, Bestani C, et al: Observational study of patients with gastroenteropancreatic and bronchial neuroendocrine tumors in Argentina: results from the large database of a multidisciplinary group clinical multicenter study. Mol Clin Oncol 2014;2:673-684.

3 Modlin IM, Lye KD, Kidd M: A 50-year analysis of 562 gastric carcinoids: small tumor or larger problem? Am J Gastroenterol 2004;99: 23-32.

4 Niederle MB, Hackl M, Kaserer K, et al: Gastroenteropancreatic neuroendocrine tumours: the current incidence and staging based on the WHO and European Neuroendocrine Tumour Society classification: an analysis based on prospectively collected parameters. Endocr Relat Cancer 2010;17:909918.

5 Yao JC, Hassan M, Phan A, et al: One hundred years after 'carcinoid': epidemiology of and prognostic factors for neuroendocrine tumors in 35,825 cases in the United States. J Clin Oncol 2008;26:3063-3072.

6 Hallet J, Law CH, Cukier M, et al: Exploring the rising incidence of neuroendocrine tumors: a population-based analysis of epidemiology, metastatic presentation, and outcomes. Cancer 2015;121:589-597.

7 Tsai HJ, Wu CC, Tsai CR, et al: The epidemiology of neuroendocrine tumors in Taiwan: a nation-wide cancer registry-based study. PLoS One 2013;8:e62487.

8 Rindi G, Arnold R, Bosman FT, et al: Nomenclature and classification of neuroendocrine neoplasms of the digestive system; in Bosman FT, et al. (eds): WHO Classification of Tumours of the Digestive System. Lyon, IARC, 2010, pp 13-14.

9 Rindi G, Bordi C, Rappel S, et al: Gastric carcinoids and neuroendocrine carcinomas: pathogenesis, pathology, and behavior. World J Surg 1996;20:168-172.
10 Cavalcoli F, Zilli A, Conte D, Ciafardini C, et al: Gastric neuroendocrine neoplasms and proton pump inhibitors: fact or coincidence? Scand J Gastroenterol 2015;10:1-7.

11 Jianu CS, Fossmark R, Viset T, et al: Gastric carcinoids after long-term use of proton pump inhibitor. Aliment Pharmacol Ther 2012;36:644-649.

12 Lahner E, Pilozzi E, Esposito G, et al: Gastric carcinoid in the absence of atrophic body gastritis and with low Ki67 index: a clinical challenge. Scand J Gastroenterol 2014;49:506510.

13 La Rosa S, Inzani F, Vanoli A, et al: Histologic characterization and improved prognostic evaluation of 209 gastric neuroendocrine neoplasms. Hum Pathol 2011;42:1373-1384.

14 Rindi G, Azzoni C, La Rosa S, et al: ECL cell tumor and poorly differentiated endocrine carcinoma of the stomach: prognostic evaluation by pathological analysis. Gastroenterology 1999;116:532-542.

15 Cavallaro A, Zanghì A, Cavallaro M, et al: The role of 68-Ga-DOTATOC CT-PET in surgical tactic for gastric neuroendocrine tumors treatment: our experience: a case report. Int J Surg 2014;12(suppl 1):S225-S231.

16 Alexander HR, Fraker DL, Norton JA, Barlett DL, Tio L, Benjamin SB, Doppman JL, Goebel SU, Serrano J, Gibril F, Jensen RT: Prospective study of somatostatin receptor scintigraphy and its effect on operative outcome in patients with Zollinger-Ellison syndrome. Ann Surg 1998;228:228-238.

17 Thomas D, Tsolakis AV, Grozinsky-Glasberg $S$, et al: Long-term follow-up of a large series of patients with type 1 gastric carcinoid tumors: data from a multicenter study. Eur J Endocrinol 2013;168:185-193.

18 Merola E, Sbrozzi-Vanni A, Panzuto F, et al: Type I gastric carcinoids: a prospective study on endoscopic management and recurrence rate. Neuroendocrinology 2012;95:207-213.

19 Uygun A, Kadayifci A, Polat Z, et al: Longterm results of endoscopic resection for type I gastric neuroendocrine tumors. J Surg Oncol 2014;109:71-74.

20 Grozinsky-Glasberg S, Thomas D, Strosberg JR, et al: Metastatic type 1 gastric carcinoid: a real threat or just a myth? World J Gastroenterol 2013;19:8687-8695.
21 Chen WF, Zhou PH, Li QL, et al: Clinical impact of endoscopic submucosal dissection for gastric neuroendocrine tumors: a retrospective study from mainland China. ScientificWorldJournal 2012;2012:869769.

22 Kobara H, Mori H, Rafiq K, et al: Indications of endoscopic submucosal dissection for symptomatic benign gastrointestinal subepithelial or carcinoid tumors originating in the submucosa. Mol Clin Oncol 2013;1:10021008.

$23 \mathrm{Kim} \mathrm{HH}$, Kim GH, Kim JH, et al: The efficacy of endoscopic submucosal dissection of type I gastric carcinoid tumors compared with conventional endoscopic mucosal resection. Gastroenterol Res Pract 2014;2014:253860.

24 Kim GH, Kim JI, Jeon SW, et al: Endoscopic resection for duodenal carcinoid tumors: a multicenter, retrospective study. J Gastroenterol Hepatol 2014;29:318-324.

25 Jianu CS, Fossmark R, Syversen U, et al: Fiveyear follow-up of patients treated for 1 year with octreotide long-acting release for enterochromaffin-like cell carcinoids. Scand J Gastroenterol 2011;46:456-463.

26 Fossmark R, Sørdal Ø, Jianu CS, et al: Treatment of gastric carcinoids type 1 with the gastrin receptor antagonist netazepide (YF476) results in regression of tumours and normalisation of serum chromogranin A. Aliment Pharmacol Ther 2012;36:1067-1075.

27 Moore AR, Boyce M, Steele IA, et al: Netazepide, a gastrin receptor antagonist, normalises tumour biomarkers and causes regression of type 1 gastric neuroendocrine tumours in a nonrandomised trial of patients with chronic atrophic gastritis. PLoS One 2013;8:e76462.

28 Kwon YH, Jeon SW, Kim GH, et al: Longterm follow up of endoscopic resection for type 3 gastric NET. World J Gastroenterol 2013;19:8703-8708.

29 Hirai M, Matsumoto K, Ueyama H, et al: A case of neuroendocrine tumor G1 with unique histopathological growth progress. World J Gastrointest Endosc 2013;5:605-609. 
30 Dinis-Ribeiro M, Areia M, de Vries AC, et al: Management of precancerous conditions and lesions in the stomach (MAPS): guideline from the European Society of Gastrointestinal Endoscopy (ESGE), European Helicobacter Study Group (EHSG), European Society of Pathology (ESP), and the Sociedade Portuguesa de Endoscopia Digestiva (SPED). Endoscopy 2012;44:74-94.

31 Niederle B, Pape UF, Costa F, Gross D, Kelestimur F, Knigge U, Öberg K, Pavel M, Perren A, Toumpanakis C, O'Connor J, O'Toole D, Krenning E, Reed N, Kianmanesh R; all other Vienna Consensus Conference participants: ENETS consensus guidelines update for neuroendocrine neoplasm of the jejunum and ileum. Neuroendocrinology 2016;103:125138.

32 Ramage JK, De Herder WW, Delle Fave G, Ferolla P, Ferone D, Ito T, Ruszniewski P, Sundin A, Weber W, Zheng-Pei Z, Taal B, Pascher A; all other Vienna Consensus Conference participants: ENETS consensus guidelines update for colorectal neuroendocrine neoplasms. Neuroendocrinology 2016; 103:139-143.
33 Pape UF, Niederle B, Costa F, Gross D, Kelestimur F, Kianmanesh R, Knigge U, Öberg K, Pavel M, Perren A, Toumpanakis C, O'Connor J, Krenning E, Reed N, O’Toole D; all other Vienna Consensus Conference participants: ENETS consensus guidelines for neuroendocrine neoplasms of the appendix (excluding goblet cell carcinomas). Neuroendocrinology 2016;103:144-152.

34 Falconi M, Eriksson B, Kaltsas G, Bartsch DK, Capdevila J, Caplin M, Kos-Kudla B, Kwekkeboom D, Rindi G, Klöppel G, Reed N, Kianmanesh R, Jensen RT; all other Vienna Consensus Conference participants: ENETS consensus guidelines update for the management of patients with functional pancreatic neuroendocrine tumors and non-functional pancreatic neuroendocrine tumors. Neuroendocrinology 2016;103:153-171.
35 Pavel M, O'Toole D, Costa F, Capdevila J, Gross D, Kianmanesh R, Krenning E, Knigge U, Salazar R, Pape UF, Öberg K; all other Vienna Consensus Conference participants: ENETS consensus guidelines update for the management of distant metastatic disease of intestinal, pancreatic, bronchial neuroendocrine neoplasms (NEN) and NEN of unknown primary site. Neuroendocrinology 2016;103:172-185.

36 Garcia-Carbonero R, Sorbye H, Baudin E, Raymond E, Wiedenmann B, Niederle B, Sedlackova E, Toumpanakis C, Anlauf M, Cwikla JB, Caplin M, O'Toole D, Perren A; all other Vienna Consensus Conference participants: ENETS consensus guidelines for high-grade gastroenteropancreatic neuroendocrine tumors and neuroendocrine carcinomas. Neuroendocrinology 2016;103:186-194. 